\title{
Gender and viability selection on morphology in fledgling pied flycatchers
}

\author{
J. POTTI, * J. A. DÁVILA, † J. L. TELLA,ł Ó. FRÍAS* and S. VILLAR* \\ *Departamento de Biología Animal, †Departamento de Biología Celular y Genética, Facultad de Biología, Universidad de Alcalá, E- \\ 28871 - Alcalá de Henares, Madrid, łEstación Biológica de Doñana, Department of Applied Biology, Apdo 1056, E-41080 Sevilla, Spain
}

\begin{abstract}
Until recently, analyses of gender-dependent differences in viability selection and the ontogeny of sexual size dimorphism have been plagued by difficulties in determining the sex of nestling birds on the basis of morphology. Recently, this problem was overcome using molecular sex identification to report for the first time body-size-mediated antagonistic selection on the viability of male and female collared flycatchers. We used molecular sex identification to analyse natural selection on fledgling viability, sexual size dimorphism and effects of parasites in relation to gender in a Mediterranean population of the related pied flycatcher Ficedula hypoleuca. There was directional positive selection on fledgling weight but no selection on tarsus length. Fledgling weight was the most important determinant of fledgling survival, with heavier fledglings having increased viability. Although selective trends were of the same sign for both sexes, only among female fledglings were selection differentials and gradients statistically significant. Therefore, similar trends in selection were revealed in analyses of a data set where sex was ignored and in separate analyses using same-sex sibship trait means. Mite nest ectoparasites negatively affected fledgling weight, and the effects were stronger in female than male fledglings. There was no effect of parasitism on the tarsus length in males, as previously reported in retrospective analyses performed without knowledge of sex until recruitment. Overall, selection on fledgling viability on the basis of morphological traits and hatching date was not confounded by an individual's gender.
\end{abstract}

Keywords: CHD1 genes, molecular sexing, natural selection, parasitism, sexual size dimorphism, tarsus length

\section{Introduction}

The recent upsurge of molecular techniques for sexing birds (Ellegren \& Sheldon 1997) has sprouted a plethora of studies on sex ratio variation among nestlings (e.g. Ellegren et al. 1996; Lessells et al. 1996; Hartley et al. 1999; Kölliker et al. 1999; Pagliani et al. 1999; Albrecht 2000; Korpimäki et al. 2000; Questiau et al. 2000). This work is throwing light on issues related to adaptive sex allocation by parents and differential costs of rearing each sex, which are predicted to be higher for the gender attaining a larger size in adulthood (Trivers \& Willard 1973). Studies using molecular sex identification are also likely to proliferate

Correspondence: Dr Jaime Potti. Fax: 349188550 80; E-mail: jaime.potti@uah.es after Merilä et al. (1997) demonstration that natural selection on fledgling morphology may act antagonistically depending on gender in some bird species, at least in some years. Sex differences apparently already exist at early ages in many strongly size-dimorphic bird species (Richner 1991), but may also be present in slightly size-dimorphic avian species, e.g. great tits, Parus major (Smith et al.1989), blue tits, Parus caeruleus (Merilä \& Svensson 1997) and pied flycatchers, Ficedula hypoleuca (Potti \& Merino 1996; Potti 1999a). Until the advent of molecular techniques to sex nestling birds, and except for those few species where nestlings can be readily sexed by size or external morphology (usually highly sex-dimorphic species; Gowaty 1991), virtually all previous work on altricial birds with slight sexual size dimorphism has forcedly ignored individual sex as a potentially important factor to 
consider in selection studies (Merilä et al. 1997; Badyaev et al. 2001). Avian ecologists interested in the early establishment of sex differences (reviewed by Lindström 1999; Badyaev et al. 2001) have therefore retrospectively analysed natural selection by looking at individuals that have passed through the filter of mortality selection between fledgling and recruitment, usually while breeding for the first time. Several studies have pointed out that those studies performed to date based exclusively on surviving individuals, whose sex-related phenotype is known only retrospectively, may give a biased picture of sexdependent selection if individuals of one sex have to be larger, heavier, or in better condition than those of the other sex in order to survive (Grant \& Grant 1989; Hochachka \& Smith 1991; Merilä \& Svensson 1997; Merilä et al. 1997; Sheldon et al. 1998; Verboven \& Visser 1998; Badyaev et al. 2001). These caveats may obviously confound the documentation and interpretation of gender differences in morphology, one of which is the establishment of sexual size dimorphism (Merilä et al. 1997; Badyaev et al. 2001). This serious methodological bias has recently been overcome with the development of molecular methods for identifying the sex of individuals (Ellegren \& Sheldon 1997).

Inspired by the study of Merilä et al. (1997) on collared flycatchers, Ficedula albicollis, we document here patterns of viability selection on nestling morphology in a southern European population of the closely related pied flycatcher (Ficedula hypoleuca) and their relationships with nestling sex. We ask whether selection acted differently in both sexes, as was documented for the collared flycatcher. Earlier retrospective analyses of fledgling growth in pied flycatchers have pointed to the possibility of sex differences in tarsus length (Potti \& Merino 1996), weight, residual indices of condition (Potti 1999a) and feather growth (Potti 2000) being already present early in the ontogeny. Merilä et al. (1997), however, did not find gender differences in morphological traits, although viability selection on morphology differed in direction between the sexes and was probably responsible for the sexual size dimorphism observed in adults.

\section{Materials and methods}

The study was carried out in 1998-2000 in an intensively studied pied flycatcher population breeding in nestboxes in La Hiruela, central Spain (see Potti \& Merino 1994). All nests were checked at regular intervals to determine exactly the laying date, clutch size, number of eggs hatched and number of young fledged.

The fledglings were ringed, measured for tarsus length (with a digital calliper, to the nearest $0.01 \mathrm{~mm}$ ) and weighed (to the nearest $0.1 \mathrm{~g}$ ) close to fledging time, at the age of 13 days, when tarsus length had attained adult size
(Alatalo \& Lundberg 1986; Potti \& Merino 1994). Although earlier studies of fledgling flycatchers have used the residuals of the regression of weight on tarsus length as indices of body condition (Alatalo et al. 1990; Lindén et al. 1992; Merino \& Potti 1995; Merilä et al.1997, 2001; Sheldon et al. 1998; Potti 1999a,b) we chose not to use them due to the considerable objections recently raised to interpretation of these indices as truly indicative of body condition (Darlington \& Smulders 2001; García-Bertheu 2001; Green 2001) and also because those residuals did not provide information unaccounted for by the other variables. Nestling mortality was assessed indirectly by substracting the number of offspring at the age of 13 days from the number hatched. To control for ectoparasite effects on fledgling growth we also scored the abundance of blood-suckling mites (Acari: Dermanyssus spp.) with categorical indices (high vs. low mite abundance) that have been shown, by means of Berlese funnels, to be highly predictive indices of the intensity of mite infestations (Merino \& Potti 1995). The effects of mite abundance on selection differentials (see below) were tested with ancova. The number of fledglings recovered breeding up to the 2000 breeding season was used as a measure of recruitment.

\section{Identification of fledgling sex}

As yet, we lack methods to tell apart male from female nestling pied flycatchers by external morphology, hence molecular methods were used. In 1998 blood samples were taken from nestlings and from adult birds to calibrate the procedure of molecular sexing. Between 40 and $60 \mu \mathrm{L}$ of blood was collected with a heparinized capillary tube from the brachial vein of all nestlings that were alive at the age of 13 days and stored in $500 \mu \mathrm{L}$ of anticoagulant preservative solution buffer (Arctander 1988). DNA was extracted from whole blood using chelex extraction (Walsh et al. 1991). The sex of birds was determined by multiplex polymerase chain reaction amplification of the CHD1 genes in the $\mathrm{W}$ and $\mathrm{Z}$ chromosomes using the primers 2945F, cfR and 3224R (Ellegren 1996). Amplification products were fractionated on $1.5 \%$ agarose gels and stained with ethidium bromide. Four nests were excluded from some analyses because of failures in the process of DNA amplification for one or more nestlings in each brood. However, they were included in other analyses where individual sex was not considered.

\section{Estimation of viability selection and statistical analyses}

Following Merilä et al. (1997), two types of analyses of survival selection in relation to fledgling sex and phenotypic characteristics were made. A first set of analyses used all fledglings, irrespective of broods, to estimate selection on survival to adulthood. We estimated survival 
by extensively capturing breeding flycatchers in all nestboxes during the 2 years after banding the fledglings, considering as survivors those individuals later recaptured ( 1 = survivor), and considering as dead those that were never recaptured $(0=$ nonsurvivor) (see Merilä et al. 1997 for the same methodology). This approach, however, may bias actual survival if some alive individuals remained unnoticed, due to their unmated status or dispersal. For assessing potential sources of variability that could affect analyses of survival selection, we estimated survival and recapture probabilities with the same data following Jolly-Seber mark-recapture models for open populations (Lebreton et al. 1992). We used the program release (White \& Burnham 1999) to assess the goodness-of-fit of the initial models $\left(\varphi_{\mathrm{s}^{*}}, p_{\mathrm{s}^{*}}\right)$, where survival $(\varphi)$ and recapture probabilities $(p)$ are both sex (s) and age (a) dependent. Tests showed homogeneity between and within groups for the data set ( $P>0.63$ for all tests), therefore our data were appropriate for a Jolly-Seber modelling approach. We then tested all potential models combining sex and age effects, including interaction terms (indicated by an asterisk between subscript factors) and additive models (indicated by plus signs). Models were built using the program mark (White \& Burnham 1999). We used Akaike's Information Criterion (AIC) to select the best-fitting model, i.e. the model with the lowest quasi-likelihood AIC value (White \& Burnham 1999).

Standardized selection differentials $(S)$ for tarsus length and weight were estimated using least squares regression of relative fitness on the traits' values previously standardized to zero mean and unit variance (Arnold \& Wade 1984a,b). Individual survival values were divided by the population mean survival rate to obtain a measure of relative fitness (Arnold \& Wade 1984a,b; Endler 1986; Price \& Boag 1987). Multiple regression was used to estimate nonlinear selection, i.e. stabilizing or disruptive selection. Stabilizing selection may be put in evidence if the regression coefficients $(\gamma)$ of squared standardized values are negative, while disruptive selection entails positive coefficients for standardized squared traits. The statistical significance of selection differentials and gradients was not derived from multiple regressions but was obtained from logistic regressions - see Price \& Boag (1987), Mitchell-Olds \& Shaw (1987) and Fairbairn \& Preziosi (1996) for the rationale under the splitting of selection analyses into parameter estimation and statistical inference.

The analyses described above treat each fledgling as an independent observation, which may incur pseudoreplication as individuals in a brood share genes and a common environment. To circumvent this problem we also analysed differences among broods on the basis of nestling sex using same-sex means of sib traits for each brood (Merilä et al. 1997). In this case, relative fitness was coded as the number of fledglings recruiting from a group of same-sex sibs divided by the sex-specific number of recruits per family (Merilä et al.1997). As these authors point out, this type of analysis is highly conservative for the detection of selection on morphology because it does not take into account phenotypic differences within same-sex sibs across families. We also used same-sex nest averages to test for the effects of parasites on fledgling traits.

Direct effects of selection on a trait may be confounded by indirect effects due to selection on correlated characters. To see which was, among the traits we measured, the true target of selection we used multiple regression analyses (Lande \& Arnold 1983) of relative fitness on fledgling weight, tarsus length and hatching date. We report selection gradients $\left(\beta^{\prime}\right)$ that give the effect of each trait on relative fitness while accounting for the effects of phenotypic correlations among the measured traits (Endler 1986).

Statistics (StatSoft 1996; SPSS 1999) are two-tailed. Throughout the text, means are given \pm 1 SD.

\section{Results}

\section{Accuracy of the sexing technique}

For the blood-sampled fledglings that recruited to the breeding population in 1999 and $2000(n=53)$ their sex had been correctly determined in all cases. This was also the case for all breeding adults of known sex that were blindly amplified by one of us (J.A.D.; $n=70$ ). Therefore, these results make us highly confident on the overall accuracy of the sexing technique.

\section{Sex and fledgling survival}

For 90 broods where one or more young attained the age of 13 days the brood sex ratio ranged from 0 to 1 , averaging $0.430 \pm 0.238$, i.e. being female-biased at the population level. Out of all sexed fledglings $(n=419), 34$ females $(14 \%)$ and 19 (10\%) males were recovered while breeding in their first or second year.

\section{Potential biases in survival estimates}

The above return rates used for morphological selection analyses might bias actual survival estimates and their relationships with morphological traits if probability of recapture varied with sex. Table 1 shows the 25 models reflecting all potential combinations of age and sex effects on both survival and recapture probabilities of fledglings. The best-fitting model showed that survival depended on age (first-year vs. second-year breeders), as expected (e.g. Sternberg 1990; Badyaev et al. 2001). However, although recapture probabilities were relatively low (especially for birds that bred in their first year), neither recapture nor survival depended on sex (Table 2). Therefore, we can 
Table 1 Survival models and associated biological hypotheses for the 419 fledgling pied flycatchers sexed through molecular procedures in 1998

\begin{tabular}{|c|c|c|c|c|}
\hline Model & Dev & np & AIC & Hypothesis \\
\hline$\varphi_{\mathrm{a},} \boldsymbol{p}_{\mathrm{a}}$ & 0.565 & 3 & 388.77 & Survival and recapture depended on age \\
\hline$\varphi_{\mathrm{a}}, p_{\mathrm{s}+\mathrm{a}}$ & 0.540 & 4 & 390.78 & Survival depended on age, additive effect of sex and age for recapture \\
\hline$\varphi_{\mathrm{s}+\mathrm{a}}, p_{\mathrm{a}}$ & 0.547 & 4 & 390.79 & Additive effect of sex and age on survival, recapture depended on age \\
\hline$\varphi, p_{\mathrm{s}+\mathrm{a}}$ & 2.685 & 3 & 390.89 & Constant survival, additive effect of sex and age on recapture \\
\hline$\varphi, p_{\mathrm{a}}$ & 2.762 & 3 & 390.97 & Constant survival, recapture depended on age \\
\hline$\varphi_{\mathrm{s}^{*} \mathrm{a}}, p_{\mathrm{a}}$ & 0.060 & 5 & 392.35 & Interaction of sex with age for survival, recapture depended on age \\
\hline$\varphi_{\mathrm{a}}, p_{\mathrm{s}^{*} \mathrm{a}}$ & 0.325 & 5 & 392.62 & Survival depended on age, interaction of sex with age for recapture \\
\hline$\varphi_{\mathrm{s}+\mathrm{a}}, p_{\mathrm{s}+\mathrm{a}}$ & 0.407 & 5 & 392.70 & Additive effect of sex and age on both survival and recapture \\
\hline$\varphi_{\mathrm{s}}, p_{\mathrm{s}+\mathrm{a}}$ & 2.655 & 4 & 392.90 & Survival depended on sex, additive effect of sex and age for recapture \\
\hline$\varphi_{\mathrm{s}}, p_{\mathrm{a}}$ & 2.746 & 4 & 392.90 & Survival depended on sex, recapture depended on age \\
\hline$\varphi_{\mathrm{s}^{*} \mathrm{a}}, p_{\mathrm{s}^{* \mathrm{a}}}$ & 0.000 & 6 & 394.35 & Interaction of sex with age for both survival and recapture \\
\hline$\varphi_{\mathrm{s}^{*} \mathrm{a}}, p_{\mathrm{s}+\mathrm{a}}$ & 0.000 & 6 & 394.35 & Interaction of sex with age for survival, additive effect of sex and age for recapture \\
\hline$\varphi_{\mathrm{s}+\mathrm{a}}, p_{\mathrm{s}^{* a}}$ & 0.000 & 6 & 394.35 & Additive effect of sex and age on survival, interaction of sex with age for recapture \\
\hline$\varphi, p_{\mathrm{s}^{*} \mathrm{a}}$ & 2.685 & 5 & 394.98 & Constant survival, interaction of sex with age for recapture \\
\hline$\varphi_{\mathrm{s}}, p_{\mathrm{s}^{*} \mathrm{a}}$ & 2.655 & 6 & 397.00 & Survival depended on sex, interaction of sex with age for recapture \\
\hline$\varphi_{\mathrm{s}+\mathrm{a}}, p$ & 13.357 & 3 & 401.56 & Additive effect of sex and age on survival, constant recapture \\
\hline$\varphi_{\mathrm{a}}, p$ & 13.364 & 3 & 401.57 & Survival depended on age, constant recapture \\
\hline$\varphi_{\mathrm{s}+\mathrm{a}}, p_{\mathrm{s}}$ & 13.205 & 4 & 403.45 & Additive effect of sex and age on survival, recapture depended on sex \\
\hline$\varphi_{\mathrm{a}}, p_{\mathrm{s}}$ & 13.348 & 4 & 403.59 & Survival depended on age, recapture depended on sex \\
\hline$\varphi_{\mathrm{s}^{*} \mathrm{a}}, p$ & 13.357 & 5 & 405.65 & Interaction of sex with age for survival, constant recapture \\
\hline$\varphi_{\mathrm{s}^{*} \mathrm{a}}, p_{\mathrm{s}}$ & 13.205 & 6 & 407.55 & Interaction of sex with age for survival, recapture depended on sex \\
\hline$\varphi, p$ & 27.385 & 2 & 413.56 & Constant both survival and recapture \\
\hline$\varphi, p_{\mathrm{s}}$ & 27.382 & 3 & 415.59 & Constant survival, recapture depended on sex \\
\hline$\varphi_{\mathrm{s}}, p$ & 27.385 & 3 & 415.59 & Survival depended on sex, constant recapture \\
\hline$\varphi_{\mathrm{s}}, p_{\mathrm{s}}$ & 27.382 & 4 & 417.62 & Survival and recapture depended on sex \\
\hline
\end{tabular}

The best-fitting model is in bold. Dev., deviance of the model; np, number of identifiable parameters; QAIC, quasi-likelihood Akaike’s information criterion. Factors considered potentially to affect survival $(\varphi)$ or recapture probabilities $(p)$ were sex (s) and age (a).

Table 2 Estimated survival and recapture probabilities for the 419 fledgling pied flycatchers banded in 1998, as resulting from the best-fitting model $\left(\varphi_{\mathrm{a}}, p_{\mathrm{a}}\right.$, see Table 1$)$

\begin{tabular}{llll}
\hline Age & Estimate & SE & CI \\
\hline $\begin{array}{l}\text { Survival } \\
\text { first-year }\end{array}$ & 0.20 & 0.05 & $0.12-0.32$ \\
$\quad$ adult & 0.71 & 0.00 & $0.71-0.71$ \\
$\begin{array}{l}\text { Recapture } \\
\text { first-year }\end{array}$ & 0.20 & & \\
$\quad$ adult & 0.66 & 0.06 & $0.11-0.36$ \\
\hline
\end{tabular}

Standard errors (SE) and 95\% confidence intervals (CI) are also shown.

safely consider that our recaptured birds were a random sample of survivors adequate for selection analyses.

\section{Selection on fledgling morphology and hatching date}

The results of univariate analyses of selection on fledgling morphological traits and hatching date are summarized in Table 3. There was a high correspondence between selection differentials calculated for all fledglings and for same-sex sib groups $(r=0.95, n=9, P<0.0001$; Table 4). Similar conclusions may therefore be reached using either data set as the unit of analysis.

These analyses revealed positive directional survival selection on fledgling weight but no selection on fledgling tarsus length (Fig. 1), as well as negative directional survival selection on hatching date (Table 3). Results were similar in analyses split by sex, although statistical significance of coefficients was only reached, or marginally approached, in females. No selection coefficient was significant for male fledglings. However, there was a close correspondence between the calculated linear selection differentials for males and females across all possible comparisons in Table $3(r=0.91, n=6, P=0.012)$. No coefficient of nonlinear selection was statistically significant.

These results suggest that selection acted in a similar way for these morphological traits in male and female fledglings. This was further tested with logistic regressions with survival as dependent variable and sex $\times$ trait interactions as predictors (Merilä et al.1997). None of the interactions reached or approached significance (tarsus length: $\mathrm{X}^{2}=1.47, P=0.69$; interaction term, $B=-0.10$, d.f. $=1, P=$ 
Table 3 Standardized linear $(S)$ and nonlinear $(\gamma)$ viability selection differentials for morphological traits and hatching date of fledgling pied flycatchers for both sexes combined and for each sex separately

\begin{tabular}{|c|c|c|c|c|c|}
\hline \multirow[b]{2}{*}{ Group } & \multirow[b]{2}{*}{ Trait } & \multicolumn{2}{|l|}{$S \pm \mathrm{SE}$} & \multicolumn{2}{|l|}{$Y \pm S E$} \\
\hline & & Nestlings & Sib-groups & Nestlings & Sib-groups \\
\hline \multirow[t]{4}{*}{ All nestlings } & tarsus length & $-0.004 \pm 0.129$ & $0.053 \pm 0.153$ & $-0.000 \pm 0.132$ & $-0.114 \pm 0.200$ \\
\hline & body weight & $0.338 \pm 0.128 * *$ & $0.449 \pm 0.146^{* *}$ & $0.128 \pm 0.126$ & $0.190 \pm 0.196$ \\
\hline & hatching date & $-0.261 \pm 0.128^{*}$ & $-0.362 \pm 0.170^{*}$ & $-0.180 \pm 0.166$ & $-0.172 \pm 0.260$ \\
\hline & $n$ & 419 & 92 & 419 & 92 \\
\hline \multirow[t]{4}{*}{ Females } & tarsus length & $-0.063 \pm 0.278$ & $-0.106 \pm 0.184$ & $-0.144 \pm 0.144$ & $-0.204 \pm 0.206$ \\
\hline & body weight & $0.303 \pm 0.123^{* *}$ & $0.577 \pm 0.173^{* *}$ & $0.146 \pm 0.140$ & $0.430 \pm 0.238$ \\
\hline & hatching date & $-0.297 \pm 0.152$ & $-0.367 \pm 0.198$ & $-0.158 \pm 0.204$ & $-0.192 \pm 0.302$ \\
\hline & $n$ & 238 & 88 & 238 & 88 \\
\hline \multirow{4}{*}{ Males } & tarsus length & $0.097 \pm 0.401$ & $-0.127 \pm 0.239$ & $0.560 \pm 0.298$ & $-0.054 \pm 0.352$ \\
\hline & body weight & $0.228 \pm 0.192$ & $0.234 \pm 0.238$ & $0.054 \pm 0.262$ & $-0.132 \pm 0.256$ \\
\hline & hatching date & $-0.196 \pm 0.232$ & $-0.355 \pm 0.264$ & $-0.202 \pm 0.292$ & $-0.142 \pm 0.406$ \\
\hline & $n$ & 181 & 80 & 181 & 80 \\
\hline
\end{tabular}

Analyses are performed on all fledglings and also on same-sex sibship averages (see Materials and methods).

${ }^{*} P<0.05 ; * * P<0.01$.

Table 4 Results of multiple regression analyses to quantify correlated viability selection on morphology and hatching date of fledgling pied flycatchers

\begin{tabular}{llll}
\hline \multirow{4}{*}{ Group } & Trait & $\begin{array}{l}\text { All individuals } \\
\beta \pm \mathrm{SE}\end{array}$ & $\begin{array}{l}\text { Sib groups } \\
\beta \pm \mathrm{SE}\end{array}$ \\
\hline \multirow{2}{*}{ All nestlings } & tarsus length & $-0.20 \pm 0.14$ & $-0.23 \pm 0.16$ \\
& weight & $0.38 \pm 0.14^{* *}$ & $0.49 \pm 0.17^{* *}$ \\
& hatching date & $-0.22 \pm 0.13$ & $-0.28 \pm 0.17$ \\
Females & $n$ & 419 & 92 \\
& tarsus length & $-0.25 \pm 0.17$ & $-0.38 \pm 0.18$ \\
& weight & $0.43 \pm 0.17^{* *}$ & $0.67 \pm 0.19^{* *}$ \\
& hatching date & $-0.25 \pm 0.15$ & $-0.31 \pm 0.19$ \\
Males & $n$ & 238 & 87 \\
& tarsus length & $-0.09 \pm 0.25$ & $-0.34 \pm 0.27$ \\
& weight & $0.28 \pm 0.25$ & $0.33 \pm 0.27$ \\
& hatching date & $-0.17 \pm 0.24$ & $-0.31 \pm 0.19$ \\
& $n$ & 181 & 79 \\
\hline
\end{tabular}

$\beta$-values are multivariate linear selection gradientcoefficients, using either all fledglings or same-sex sibships as units of analysis. $* * P<0.01$.

0.74; weight: $X^{2}=9.17, P=0.03$; interaction term, $B=0.18$, d.f. $=1, P=0.62$ ).

To see which traits among those we measured were the true target of selection we used multiple regression (Table 4). Using either of the data sets (individual fledglings or same-sex sibs) only fledgling weight significantly explained survival, the heavier fledglings having increased viability. As in univariate analyses, only coefficients for all fledglings, irrespective of gender, and for female fledglings were significant, although the sign of coefficients for male weight and hatching date indicated the same direction of selection as for females. Thus, although selection gradients for hatching date were negative and relatively large, the significant univariate selection on hatching date was presumably a result of correlated selection on fledgling weight as this decreased with an advancing hatching date $(r=-0.23$, $n=92$ broods, $P=0.03$ ).

\section{Sexual size dimorphism among fledglings}

Considering all fledglings, there were no statistically significant differences between sexes in tarsus length (males: $19.59 \pm 0.55$; females: $19.60 \pm 0.58$; $t$-test, $t=-0.18, P=0.86$ ) or weight (males: $14.63 \pm 1.14$; females: $14.66 \pm 1.23$; $t=-0.14$, $P=0.89)$. Neither did the allometric relationship between weight and tarsus differ between the sexes $\left(F_{1,418}=0.01, P=\right.$ 0.94). However, more powerful paired $t$-tests comparing sib groups of each sex weighed by the number of individuals composing each group revealed that the tarsus length of male fledglings was slightly, though significantly, shorter than that of their female sibs (males: $19.58 \pm$ $0.49 \mathrm{~mm}$; females: $19.67 \pm 0.48 \mathrm{~mm} ; t=-2.01$, d.f. $=77$, $P=0.048)$. Sexes did not differ significantly, however, in weight $(t=0.04, P=0.96)$.

\section{Effects of parasitism by mites on male and female fledglings}

Ectoparasitism by mites significantly affected the numbers of female, but not male, fledglings that returned to breed: not a single female returned from broods that had been heavily infested by mites (Kruskal-Wallis anova, $H=$ 6.36, $P=0.012$ ) while male numbers did not differ in relation to mite abundance $(H=1.55, P=0.21)$. In addition, 

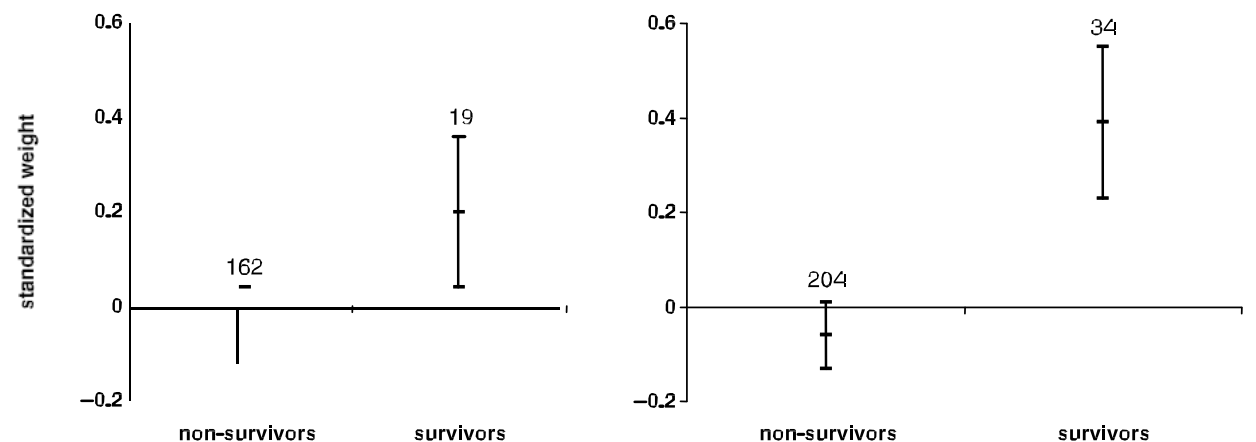

survivors

non-survivors

survivors
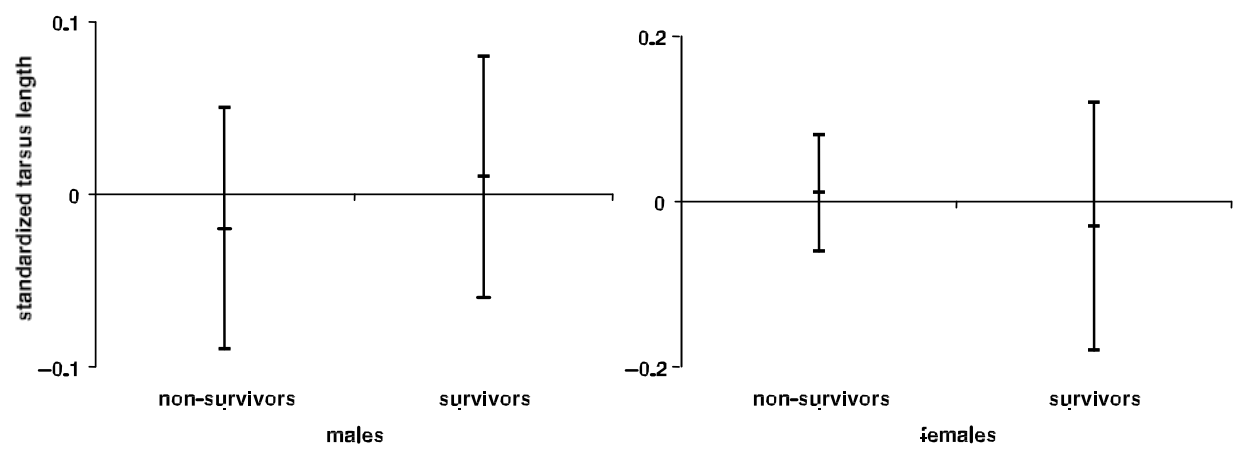

Fig. 1 Mean $( \pm 1$ SE) standardized weight and tarsus lengths of male and female fledgling pied flycatchers in relation to survival to recruitment as breeders. Figures are numbers of fledglings.

Table 5 Effects of the abundance of nest mite ectoparasites on fledgling traits

\begin{tabular}{|c|c|c|c|}
\hline & $F$ & d.f. & $P$ \\
\hline \multicolumn{4}{|l|}{ Brood means } \\
\hline tarsus length & 0.94 & 1,88 & 0.345 \\
\hline weight & 6.06 & 1,88 & 0.016 \\
\hline \multicolumn{4}{|l|}{ Male fledglings } \\
\hline tarsus length & 0.08 & 1,75 & 0.781 \\
\hline weight & 3.84 & 1,75 & 0.054 \\
\hline \multicolumn{4}{|l|}{ Female fledglings } \\
\hline tarsus length & 0.21 & 1,83 & 0.656 \\
\hline weight & 9.64 & 1,83 & 0.003 \\
\hline
\end{tabular}

$F$-values from ancovas of fledgling traits in relation to high ( $n=13)$ or low $(n=76)$ abundance of mites on pied flycatcher nests while controlling for hatching date. In all cases, significant differences denote higher values of fledgling traits in nests uninfested by mites.

controlling for the significant (or marginally significant) trends for shorter tarsi $(r=-0.18, P=0.08)$ and lower weights $(r=-0.23, P=0.03)$ with an advancing hatching date by means of ancovas, mites had an overall significant detrimental effect on fledgling weight but no effect on tarsus length (Table 5), with no significant interactions between fledgling sex and parasites on the expression of both traits (tarsus length: $F_{1,397}=1.73, P=0.19$; weight: $F_{1,397}=2.37, P=0.12$ ). Neither was there a significant effect of mite abundance on relative fitness, either for broods $\left(F_{1,84}=0.08, P=0.78\right)$ or for male or female sib groups considered separately $\left(F_{1,71}=2.27, P=0.14\right.$, and $F_{1,83}=$ $1.88, P=0.17$, respectively).

\section{Discussion}

Studies on natural selection on fledgling morphology are commonly based on the return of individuals to the natal population as estimators of individual survivorship (e.g. Alatalo et al. 1990; Lindén et al. 1992; Merilä et al. 1997; Potti 1999a). However, return rates usually underestimate actual survival because a number of surviving individuals remain unnoticed (Martin et al. 1995), and thus genderdependent natural selection on viability could be masked were recapture probability to differ between sexes. Through capture-recapture models, we obtained relatively low, but constant, probabilities of recapture for males and females. When recapture is low but constant, return rates estimate incorrect intercepts (and underestimate survival), but they estimate the correct correlations and slopes for relationships between survival and traits such as morphological traits (Martin et al. 1995). Furthermore, the 
misassignment of unnoticed, dispersing individuals to the nonsurvivors group should not be a problem in this respect as we have shown elsewhere that natal dispersal is unrelated to fledgling morphology in either sex in this population (Potti \& Montalvo 1991). Altogether, this makes us confident that our data set of recaptured individuals was appropriate for gender-dependent analyses of natural selection.

We have shown that natural selection on fledgling viability in a population of pied flycatchers acted directionally on weight but not on tarsus length, a measure of skeletal size (Senar \& Pascual 1997), as well as on hatching date. In addition, selection on fledgling phenotypic traits near independence acted in a similar direction in both sexes, although the intensity of selection on the measured traits differed, apparently being stronger in females. Therefore, between-sex concordant patterns of selection suggest that fledgling sex was not a factor confounding selection on morphology in this population, at least in the year of study. We will first discuss the possibility of biases in our data that may have influenced the observed differences in selection intensity between sexes.

A potential bias in our results is the age of first breeding of the 1998 cohort that, although not significantly, tended to differ between the sexes. In our population, more males than females tend to breed for the first time when aged 2 years (Potti \& Montalvo 1991; this study), which means that male fledglings that survived to their first potential breeding season but did not mate, and then died, were erroneously ascribed to the nonsurvivors group. In that sense, pairing selection might confound data on viability selection for males. However, the trends in selection differentials and gradients of the male traits we measured were overall coincident with those observed in females, indicating positive directional selection on weight. For mating selection to confound viability selection, assuming that the weight of individuals is repeatable across years (e.g. Potti 1999a,b; J. Potti, unpublished data), males that remained unmated in their first breeding season should have remained unmated because of being heavier or in better condition than mated males. Conceivably, this could be a possible outcome of a life-history model where it might pay good quality individuals to defer reproduction to the second year while poor quality individuals may be selected to breed as soon as possible. However, current evidence on reproductive fitness and age of first breeding in pied flycatchers does not support this possibility (Harvey et al. 1988). Thus, we conclude that mating selection should not have biased our interpretation of sex differences, or lack thereof, in this population. However, sex differences in the age of first reproduction may have affected our estimates on selection intensity in males by lowering the sample size of recruited males and hence the power of statistical tests to detect it.
In common with other studies on muscicapid flycatchers, hatching date apparently influenced recruitment to age at first breeding (Potti \& Montalvo 1991; Lindén et al. 1992; Merilä et al. 1997). Fledgling survival tended to decrease with an advanced hatching date, illustrating once again a pervasive pattern across avian species (e.g. Perrins 1965; Cooke et al. 1995; Verboven \& Visser 1998). However, it has been noted (e.g. Verboven \& Visser 1998) that selection on fledgling weight could be confounded by selection on hatching date because fledgling weight may itself decline with date, as was also the case in our study. This was evidenced in our multivariate selection analyses indicating that fledgling weight was the target of selection in both sexes, though only significantly in females, so that heavier fledglings had increased viability independently of their date of birth. This concurs with earlier findings for the species in a British population (Lundberg \& Alatalo 1992), as well as with results on viability selection on the related collared flycatcher in Gotland (Lindén et al. 1992; but see Merilä et al. 1997).

As to the other body trait we measured, survival was independent of tarsus length, a character that probably has a moderate to large additive genetic component in this (Potti \& Merino 1994) and other populations of pied flycatchers (Lundberg \& Alatalo 1992). For instance, the heritability ( $h^{2}$; Falconer 1989; Lynch \& Walsh 1998) of tarsus length in the year of study, calculated from midparentmidoffspring regression, was $h^{2}=0.80$ (SE 0.13, $n=89$ families). The absence of selection on tarsus length in the face of significant heritability of the trait means that the predicted response to selection is zero, which would constrain evolution of the trait. However, genetic correlations between traits may drive the evolution of correlated traits even if direct selection on some of them is absent (e.g. Endler 1986; Falconer 1989). Theoretically, tarsus length could undergo evolutionary change in our population through a correlated response to selection on weight, which was the target of directional selection on fledgling viability in the present study. Some hint of the possibility of correlated selection on tarsus length is given by the phenotypic correlation between both traits, which is moderate $(r=0.43$, $n=419, P<0.0001$ ). Assuming that weight as a fledgling and as an adult are comparable traits (Potti 1999a,b), an approximation to the genetic correlation $\left(r_{\mathrm{A}}\right.$; Lynch \& Walsh 1998) between tarsus length and weight can be computed, giving a value of $r_{\mathrm{A}}=0.17$ that, although low, leaves scope for evolutionary change in tarsus length via correlated selection on fledgling weight. However, our multivariate analyses were clear in indicating that directional selection on fledgling weight was not confounded by correlated selection on tarsus length. Furthermore, an 18-year analysis of microevolutionary trends in this population has shown that fledgling and adult tarsus lengths have remained unchanged, while body masses have been 
a significant target of selection (J.J. Sanz et al. unpublished results). An analogous result was obtained by Alatalo et al. (1990) who argued that apparent viability selection on tarsus length in their Scandinavian pied and collared flycatcher populations acted on the environmental, not the genetic, component of tarsus length (but see Merilä et al. 2001). Note, furthermore, that the presence of significant heritability of tarsus length in the absence of selection in our population is consistent with the so-called Fisher's fundamental theorem of natural selection (Fisher 1930; Merilä \& Sheldon 2000), which postulates high heritability for traits unrelated to fitness because additive genetic variance has not been eroded by selection. Alternatively, high levels of additive genetic variance in tarsus length could be due to low levels of residual (environmental and dominance) variance in traits unrelated to fitness (e.g. tarsus length) as compared with fitness-related traits (see Merilä \& Sheldon (1999, 2000) for further discussion).

We have previously analysed sexual size dimorphism at the fledgling stage in the same population using recruited fledglings, i.e. those who have passed through the filters of both viability and pairing selection. In these retrospective analyses we found that female fledglings that recruited were larger than their male counterparts in both tarsus length (Potti \& Merino 1996) and wing and first-primary feather (Potti 2000), but were lighter than males, in particular under stressful conditions such as those caused by parasitism (Potti 1999a). Furthermore, male fledglings seemed to be more affected than females by the effects of parasites, growing shorter tarsi in heavily mite-infested nests. The effect was not so strong for female fledglings, pointing to differences in gender sensitivity to environmental factors during growth (Potti \& Merino 1996). The slight sexual dimorphism in tarsus length (females $>$ males) usually encountered among adult Ficedula flycatchers, both pied (Potti 1999a) and collared (Merilä et al. 1997), was already established in fledglings in our study, as opposed to the collared flycatchers studied by Merilä et al. (1997), but was independent of parasitism in the study year. We detected some evidence for sexual differences in recruitment and growth under conditions of high nest mite infestations, although there was no indication of reduced tarsus length in males under these conditions (Potti \& Merino 1996).

Overall, the results of the present study are somewhat equivocal but do not lend support to the idea of large gender differences in selection intensity on morphological traits (Merilä et al. 1997), our evidence being more inconclusive as to sex-dependent environmental sensitivity of those traits (Potti \& Merino 1996; Potti 1999a; cf. Sheldon et al. 1998). Tarsus length was unaffected by nest mite ectoparasites in both males and females, contrary to the pattern we have observed in most, but not all, previous years (Merino \& Potti 1995, 1996; Moreno et al. 1999; Potti et al. 1999). We have no explanation for the absence of effects of mites on tarsus length in the study year, except for pointing out the possibilities that parasites may differentially affect different host traits in different years (e.g. Merino \& Potti 1996) or, alternatively, that hosts may differentially allocate resources to growth of different structures (Hochachka \& Smith 1991; Potti 1999a; Badyaev et al. 2001) in different years.

To conclude, some confirmation for differential gender sensitivity in fledgling growth was directly assessed in this study, although not all the evidence was consistent with that reported in earlier analyses performed without knowledge of fledgling sex until recruitment. Thus, this study clearly illustrates the usefulness of molecular sex identification to falsify hypotheses based on retrospective analyses where sex was ignored (e.g. Potti \& Merino 1996). We found no support for the idea that antagonistic viability selection on male and female body size, as found in the collared flycatcher (Merilä et al. 1997) may underlie the existence of sexual size dimorphism in the pied flycatcher.

\section{Acknowledgements}

We are very grateful to Jacinto Gamo for friendship and generous use of his four-wheel drive vehicle. We thank a referee for constructive comments. The study was supported by project DGICYT PB97-1233-C02-01 (to J. Moreno). During writing J.P. was supported by Universidad de Alcala's project $17 \mathrm{H}$.

\section{References}

Alatalo RV, Lundberg A (1986) Heritability and selection on tarsus length in the pied flycatcher Ficedula hypoleuca. Evolution, 40, 574-583.

Alatalo RV, Gustafsson L, Lundberg A (1990) Phenotypic selection on heritable size traits: environmental variance and genetic response. American Naturalist, 135, 464-471.

Albrecht DJ (2000) Sex ratio manipulation within broods of house wrens, Troglodytes aedon. Animal Behaviour, 59, 1227-1234.

Arctander P (1988) Comparative studies of avian DNA by restriction fragment length polymorphisms analysis: convenient procedures on blood samples from live birds. Journal für Ornithologie, 29, 205-216.

Arnold SJ, Wade MJ (1984a) On the measurement of natural and sexual selection: theory. Evolution, 38, 709-719.

Arnold SJ, Wade MJ (1984b) On the measurement of natural and sexual selection: applications. Evolution, 38, 720-734.

Badyaev AV, Whittingham L, Hill GE (2001) The evolution of sexual size dimorphism in the house finch. III. Developmental basis. Evolution, 55, 176-189.

Cooke F, Rockwell RF, Lank DB (1995) The Snow Geese at la Pérouse Bay. Oxford University Press, Oxford.

Darlington RB, Smulders TV (2001) Problems with residual analysis. Animal Behaviour, 62, 599-602.

Ellegren H (1996) First gene on the avian W chromosome (CHD) provides a tag for universal sexing of non-ratite birds. Proceedings of the Royal Society of London, 263, 1635-1641. 
Ellegren H, Sheldon BC (1997) New tools for sex-identification and the study of sex-allocation in birds. Trends in Ecology and Evolution, 12, 255-259.

Ellegren H, Gustafsson L, Sheldon BC (1996) Sex ratio adjustment in relation to parental attractiveness in a wild bird population. Proceedings of the National Academy of Sciences of the USA, 93, 11723-11728.

Endler JA (1986) Natural Selection in the Wild. Princeton University Press, Princeton.

Fairbairn DJ, Preziosi RF (1996) Sexual selection and the evolution of sexual size dimorphism in the water strider Aquaris remigis. Evolution, 50, 1549-1559.

Falconer DS (1989) Introduction to Quantitative Genetics, 3rd edn. Longmann, London.

Fisher RA (1930) The Genetical Theory of Natural Selection. Clarendon Press, Oxford.

García-Bertheu E (2001) On the misuse of residuals in ecology: testing regression residuals vs. the analysis of covariance. Journal of Animal Ecology, 70, 708-711.

Gowaty PA (1991) Facultative manipulation of sex ratios in birds: rare or rarely observed?. In: Current Ornithology, Vol. 8 (ed. Power DM), pp. 141-171. Plenum, New York.

Grant BR, Grant PR (1989) Evolutionary Dynamics of a Natural Population. Chicago University Press, Chicago.

Green AJ (2001) Mass/length residuals: measures of body condition or generators of spurious results? Ecology, 82, 1473-1483.

Hartley IR, Griffith SC, Wilson K, Shepherd M, Burke T (1999) Nestling sex ratios in the polygynously breeding corn bunting Miliaria calandra. Journal of Avian Biology, 30, 7-14.

Harvey PH, Stenning MJ, Campbell B (1988) Factors influencing reproductive success in the pied flycatcher. In: Reproductive Success. Studies of Individual Variation in Contrasting Breeding Systems (ed. Cluttton-Brock TH), pp. 189-200. University of Chicago Press, Chicago.

Hochachka W, Smith JNM (1991) Determinants and consequences of nestling condition in song sparrows. Journal of Animal Ecology, 60, 995-1008.

Kölliker M, Heeb P, Werner I, Mateman AC, Lessells CM, Richner $\mathrm{H}$ (1999) Offspring sex ratio is related to male body size in the great tit (Parus major). Behavioral Ecology, 10, 68-72.

Korpimäki E, May CA, Parkin DT, Wiehn J (2000) Environmentaland parental condition-related variation in sex ratio of kestrel broods. Journal of Avian Biology, 31, 128-134.

Lande R, Arnold SJ (1983) The measurement of selection on correlated characters. Evolution, 37, 1210-1226.

Lebreton J-D, Burnham KP, Clobert J, Anderson DR (1992) Modeling survival and testing biological hypotheses using marked animals: a unified approach with case studies. Ecological Monographs, 62, 67-118.

Lessells CM, Mateman AC, Visser J (1996) Great tit hatchling sex ratios. Journal of Avian Biology, 27, 135-142.

Lindén M, Gustafsson L, Pärt T (1992) Selection on fledging mass in the collared flycatcher and the great tit. Ecology, 73, 336343.

Lindström J (1999) Early development and fitness in birds and mammals. Trends in Ecology and Evolution, 14, 343-347.

Lundberg A, Alatalo RV (1992) The Pied Flycatcher. T \& A D Poyser, London.

Lynch M, Walsh B (1998) Genetics and Analysis of Quantitative Traits. Sinauer Associates, Sunderland.

Martin TE, Clobert J, Anderson DR (1995) Return rates in studies of life history evolution: are biases large? Journal of Applied Statistics, 22, 863-875.

Merilä J, Sheldon BC (1999) Genetic architecture of fitness and non-fitness traits - empirical patterns and development of ideas. Heredity, 83, 103-109.

Merilä J, Sheldon BC (2000) Lifetime reproductive success and heritability in nature. American Naturalist, 155, 301-310.

Merilä J, Svensson E (1997) Are fat reserves in migratory birds affected by condition in early life? Journal of Avian Biology, 28, 279-286.

Merilä J, Sheldon BC, Ellegren H (1997) Antagonistic natural selection revealed by molecular sex identification of nestling collared flycatchers. Molecular Ecology, 6, 1167-1175.

Merilä J, Kruuk JL, Sheldon BC (2001) Cryptic evolution in a wild bird population. Nature, 412, 76-79.

Merino S, Potti J (1995) Mites and blowflies decrease growth and survival in nestling pied flycatchers. Oikos, 73, 95-103.

Merino S, Potti J (1996) Weather dependent effects of nest ectoparasites on their bird hosts. Ecography, 19, 107-113.

Mitchell-Olds T, Shaw RG (1987) Regression analysis of natural selection: statistical inference and biological interpretation. Evolution, 41, 1149-1161.

Moreno J, Merino S, de Potti J, León A, Rodríguez R (1999) Maternal energy expenditure does not change with flight costs or food availability in the pied flycatcher (Ficedula hypoleuca): costs and benefits for nestlings. Behavioral Ecology and Sociobiology, 46, 244-251.

Pagliani AC, Lee PLM, Bradbury RB (1999) Molecular determination of sex-ratio in yellowhammer Emberiza citrinella offspring. Journal of Avian Biology, 30, 239-244.

Perrins CM (1965) Population fluctuations and clutch size in the great tit, Parus major. Journal of Animal Ecology, 44, 553-573.

Potti J (1999a) Environmental factors and sexual differences in mass and condition of nestling pied flycatchers Ficedula hypoleuca. Écoscience, 6, 19-24.

Potti J (1999b) Maternal effects and the pervasive impact of nestling history on egg size in a passerine bird. Evolution, 53, 279-285.

Potti J (2000) Sexual size dimorphism and sources of variation in the growth of wing feathers in nestling pied flycatchers Ficedula hypoleuca. Ardeola, 47, 37-47.

Potti J, Merino S (1994) Heritability estimates and maternal effects on tarsus length in pied flycatchers, Ficedula hypoleuca. Oecologia, 100, 331-338.

Potti J, Merino S (1996) Parasites and the ontogeny of sexual size dimorphism in a passerine bird. Proceedings of the Royal Society of London, 263, 9-12.

Potti J, Montalvo S (1991) Return rate, age at first breeding and natal dispersal of pied flycatchers Ficedula hypoleuca in Central Spain. Ardea, 79, 419-428.

Potti J, Moreno J, Merino S, Frías Ó, Rodríguez R (1999) Environmental and genetic variation in the haematocrit of fledgling pied flycatchers Ficedula hypoleuca. Oecologia, 120, 1-8.

Price TD, Boag PT (1987) Selection on natural populations of birds. In: Avian Genetics: a Population and Ecological Approach (eds Cooke F, Buckley PA), pp. 257-287. Academic Press, London.

Questiau S, Escaravage N, Eybert MC, Taberlet P (2000) Nestling sex ratios in a population of Bluethroats Luscinia svecica inferred from AFLP? analysis. Journal of Avian Biology, 31, 8-14.

Richner H (1991) The growth dynamics of sexually dimorphic birds and Fisher's sex ratio theory: does sex-specific growth 
contribute to balanced sex ratios? Functional Ecology, 5, 1928.

Senar JC, Pascual J (1997) Keel and tarsus length may provide a good predictor of avian body size. Ardea, 85, 269-274.

Sheldon BC, Merilä J, Lindgren G, Ellegren H (1998) Gender and environmental sensitivity in nestling collared flycatchers. Ecology, 79, 1939-1948.

Smith HG, Källander H, Nilsson J-Å (1989) The trade-off between offspring number and quality in the Great Tit Parus major. Journal of Animal Ecology, 58, 383-401.

SPSS Inc. (1999) SPSS for Windows, Version 9.0.1. Prentice Hall, New Jersey.

StatSoft Inc (1996) Statistica for Windows, Release 5.1 (Computer Program Manual). StatSoft Inc., Tulsa, OK.

Sternberg H (1990) Pied flycatcher. In: Lifetime Reproduction in Birds (ed. Newton I), pp. 55-74. Academic Press, London.
Trivers RL, Willard DE (1973) Natural selection on parental ability to vary the sex ratio of offspring. Science, 179, 90-92.

Verboven N, Visser ME (1998) Seasonal variation in local recruitment of great tits: the importance of being early. Oikos, 81, 511524.

Walsh D, Metzger A, Higuchi R (1991) Chelex 100 as a medium for simple extraction of DNA for PCR-based typing from forensic material. Biotechniques, 10, 506-513.

White GC, Burnham KP (1999) Program MARK: survival estimation from populations of marked animals. Bird Study, $\mathbf{4 6}$ (Suppl.), 120-138.

This research is part of a senior author's programme on the evolutionary ecology of the pied flycatcher. 